\title{
Mobile Learning: Using SMS in Educational Contexts
}

\author{
Adelina Moura and Ana Amélia Carvalho \\ University of Minho \\ Campus de Gualtar \\ 4710-057 Braga, Portugal \\ adelina8@gmail.com, aac@ie.uminho.pt
}

\begin{abstract}
The Short Message Service (SMS) technology is one of the most powerful mobile technologies in current usage. Most students own a mobile phone with free SMS which can be used for learning. In this paper we explain how we used SMS for teaching and learning languages (both native and foreign). The conducted experiment presented a range of opportunities for integrating text into teaching and learning strategies and for demystifying the use of SMS in educational contexts. Via SMS technology we can deliver several learning activities to students easily and immediately. The research findings showed that students had positive perceptions about the experiment and SMS use for learning improvement and the use of their own mobile phone as a learning tool. All groups showed interest in receiving educational content via SMS. Some students greatly improved their language learning performance.
\end{abstract}

Keywords: Mobile learning, SMS, mobile phones, mobile contents, language learning.

\section{Introduction}

Never before in the history of education, has a technology been so rapidly adopted as mobile technologies. The evolution of wireless communication has created a new educational paradigm called mobile learning (m-learning). This includes the use of mobile devices (phone, PDA, pocket PC and media players like the iPod) for educational purposes [1]. Mobile learning experiences can take many forms and have different objectives. The goal is not to challenge or replace other forms of interaction, it is a complementary methodology that can support, enrich and enhance the learning experience.

Statistics show that more than 3 billion people around the world own a mobile phone. The penetration of mobile devices into many European countries exceeds $90 \%$ and younger generations seem to be the most dependent on this device for communication [2]. However, according to Schick [3], most people with mobile phones only use their basic functions, such as voice communication and SMS.

SMS technology is a reliable communication system and popular among mobile phone users. It has become a trend as a means of communication throughout the world, even in less developed countries. It has been considered by several authors [1], [2], [4] as an appropriate tool for education. 
Several studies, such as [5], [6], [7], [8], [9], [10], [11], [12], [13] suggest the integration of SMS by educational institutions to maintain contact with students in teaching and learning contexts. In this paper we present a learning environment supported by SMS for learning languages (Portuguese as mother tongue, and French as foreign language). We designed this study based on a few teaching and learning projects by SMS described above.

\section{Mobile Learning: A New Concept in Education}

The use of mobile phones and other mobile devices is having an impact on where learning takes place in many areas and contexts, including language learning [14]. Mobile technologies do not depend on a fixed location and are enable users to learn or access information. This helps maximise significant changes in teaching and learning practices.

A number of publications over the last decade [13], [14], [15], [16], [17] show that mobile learning is a growing field with interest in many areas, particularly education. Although there is no consensus on the definition of mobile learning, because it is a rapidly evolving field and due to the ambiguity of the term mobile [14], experiments and pilot studies have been conducted in this field in recent years. While the term learning is undoubted, the mobile concept can refer to the mobility of the learner as well as the mobility of content. In this sense, mobility should not only be understood in terms of spatial movement, but also in terms of processing time and without physical boundaries, thus widening the horizons of learning and information access.

Despite the fact that m-learning focuses heavily on mobility, the most important aspect is its educational effect. Through appropriate technology, learners can participate in activities directly related to their needs and contexts (just-in-time learning). This forces educators to rethink teaching and learning processes.

\section{SMS: A Technology for Learning in the Digital Age}

The adoption of SMS as an educational resource has become popular in recent years [18]. SMS is a technology that allows mobile phones to send and receive short text messages. The original size of the messages was 160 characters, but the latest mobile phone models support can receipt of messages with up to 612 characters.

Recently there has been much interest from academic institutions regarding the use of mobile technologies to support teaching and learning. The evolution of mobile devices, although not designed specifically for education, is increasing opportunities in education, with the potential for mobile learning contexts [12]. One example with great educational potential is sending an SMS via mobile phone that has great educational potential [2], thus meeting the needs of society in the digital age. Over the last decade, various SMS-based projects have been created to support the teaching and learning process, particularly in language learning.

\subsection{SMS-Based Projects in Educational Institutions}

Several studies and experiments regarding the use of SMS in different educational contexts have taken place during recent years. The following examples constitute the basis for this project. 
An experiment was conducted by Naismith [8] in a university context based on sending SMS messages to students about the cancellation of classes, information, reminders, and academic pursuits. This administrative communication with students was positive and staff expected to extend this project to other institutional sectors. In another study, a tool was implemented for communication and discussion [5] based on sending SMS messages via PDA that aimed to initiate discussions and collaborative work. Results showed that the technology improved collaborative work in literature courses. A study conducted by Song [9] explored the role of SMS in learning the vocabulary of English as a foreign language. This involved ten participants and the final results showed a significant improvement in the students' performance and their attitude towards the use of SMS in learning vocabulary. Another experiment conducted by Nix et al. [10] showed the success achieved by using SMS messages to reduce early abandonment of courses by university students. It seems that sending SMS messages to students identified as being at risk was successful in helping retain students in the system.

The TXT-2-LRN system, developed by Scornavacca et al. [11], based on SMS allows the interaction between students and teachers in the classroom. Students can send questions and comments to the teacher's computer via SMS. The project PLS TXT UR Thoughts, conducted by Markett et al. [7], allowed students to send SMS in real time through their personal mobile phones during class and online after school and encouraged interactivity with the classroom.

Other authors, such as Goh \& Hooper [18], explored the feasibility of using SMS in mobile phones to promote learning through the use of crossword SMS environments in the classroom, with positive participation.

\subsection{SMS and m-Learning}

Since mobile phones and SMS communication are so popular outside school we only need to combine these two technologies, import them, and adopt them in educational contexts. SMS is a part of m-learning (fig.1).

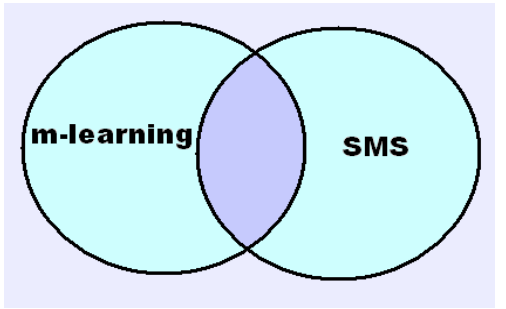

Fig. 1. SMS a part of m-learning (adapted from Lominé \& Buckhingham [1])

In initial conversations with students about using SMS in an educational environment, the reaction is one of unfamiliarity, but this awkwardness will diminish following contact with activities and realising the benefits of using it. What is important is that we ensure the educational value of this resource by delivering useful content and 
creating teaching strategies for students. Mobile phones have become a "high tech" device because they have a camera, Internet access, and the ability to install a large number of applications. SMS is considered "low tech", when compared to the use of sound, images and videos which will make m-learning more creative and dynamic, particularly in language learning, but it should not be neglected. In addition to mobility SMS presents other advantages [1]:

i) it forces users to express themselves concisely;

ii) the written text uses very little memory thus keeping costs to a minimum;

iii) using it does not require technical learning.

\subsection{The Use of SMS for Learning Languages}

Several authors [4], [6], [9], [19] consider SMS technology to be suitable for language learning. The possibility for students to access useful information anywhere and anytime is a potential of SMS technology [1]. Mobile devices, particularly mobile phones, are ideal for the promotion of learning by sending students SMS learning units in hours and days planned to optimize their free time.

A study was conducted based on learning Italian via SMS in an Australian university [6]. Students were sent new words, definitions and examples of words in context by SMS. Students could read these materials in between classes. The final remarks presented positive results.

Another study, conducted by Lu [20], reported the use of SMS for learning English as a foreign language in Taiwan. Messages containing vocabulary were sent to students during their lessons. They read the messages regardless of location and time. Students showed a preference for learning through the mobile phone rather than the computer because mobiles are more convenient than PCs in many situations.

In Japan, Thornton \& Houser [21] conducted a study using SMS and e-mail to teach English vocabulary. Teachers introduced five words weekly as well as messages sent with mini-lessons three times a day via SMS. The lessons included learning simple terms, some explanatory words, and a review of the words learned. This provided a positive result in learning new English words.

An experiment was carried out with SMS to support the learning of technical vocabulary [22]. Spaced repetitions of the same message were sent on different days through an SMS-based system called MOLT (mobile learning tool) and developed by the authors. Results showed that students enjoyed the experiment and learned new words with the help of their mobile phones.

\section{Using SMS for Language Learning: Infrastructure}

In order to develop the learning-via-SMS experiment we started with ideas presented by some authors [2], [4] together with the fact that most students always have their mobile phone with them and use it mainly to communicate via SMS. Three objectives guided this project: 
i) to integrate the phone as a learning tool;

ii) to explore a learning environment for SMS to promote language learning inside and outside the school;

iii) to encourage students to participate spontaneously and independently in learning outside of the classroom.

This experience of learning via SMS allowed individual or group SMS messages to be sent. Student phone numbers were stored in a computer database which allowed teachers to send quick messages to each individual student or to the whole group.

The model was based on the Vodafone "SMS by Mail" system in order to provide students with curricular content units and other information via SMS. The SMS messages were written in Outlook on the teacher's computer and sent via the SMS by Mail system to student's mobile phones, to be read, stored and responded. The students in turn sent the replies to the teacher's mobile phone (fig. 2).
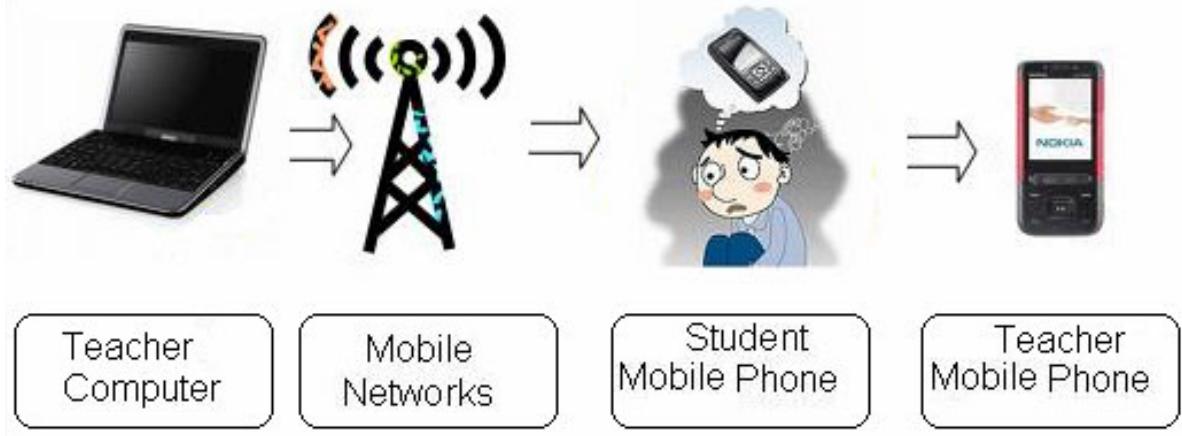

Fig. 2. SMS learning infrastructure

\section{Study Description}

The reported study was an exploratory one and was part of a larger study on the use of mobile phones as learning tools. We used a qualitative research methodology, with multiple cases using new educational technologies [23].

Once we had verified that all students owned a mobile phone, and that the majority had contracts with the same provider, with free SMS between SIM cards on the same network, we felt we had met the conditions for developing a learning environment by SMS in Portuguese and French classes. For about six weeks, text messages were sent daily, three-times a day, in a schedule agreed upon with students. The activities were divided into three scenarios:

i) units of learning to read and store on mobiles not requiring student response;

ii) activities that ask questions or demand tasks;

iii) activities including collaborative tasks (table 1).

The activities were spread over the duration of the experiment. Approximately one hundred messages were sent and more than nine hundred received. 
Table 1. Three scenarios of activities by SMS

\begin{tabular}{lll}
\hline $\begin{array}{c}\text { Scenario 1 } \\
\text { Learning unities to read and } \\
\text { store }\end{array}$ & \multicolumn{1}{c}{$\begin{array}{c}\text { Scenario 2 } \\
\text { Requesting Activities }\end{array}$} & $\begin{array}{c}\text { Scenario 3 } \\
\text { Collaborative Activities }\end{array}$ \\
\hline - Thoughts & - Quizzes & - Writing a collaborative \\
- Curricular Contents & - "Who Wants to Be a & micro story at a distance \\
- Word of the Day (Dictionary) & Millionaire" & - Writing a collaborative \\
& - Read Daily - (fables) & micro story face-to-face \\
& - Riddles & \\
\hline & - Proverbs & \\
\hline
\end{tabular}

\subsection{Data Collection}

Data collection was conducted through two questionnaires, individual interviews, and focus groups. The opinion questionnaire was answered at the end of the experiment and aimed to collect information about students' perceptions regarding the activities carried out by SMS. The questionnaire used closed questions (dual or multiplechoice), open-ended questions and a Likert scale with five levels (strongly disagree to strongly agree). The individual interviews and focus groups were conducted at the end of the study.

\subsection{Sample Characterization}

This study took place in the school year 2008/2009, both in Escola Secundária Carlos Amarante and Escola Profissional de Braga, and was attended by four groups (table 2), aged 15 to 20 in groups A, B, and C. Those aged between 22 and 56 composed group D. A total of 68 students participated in this study, $46 \%$ female and $54 \%$ male. Participants of Group B were from a private vocational school and the other groups were from a public high school. Participants from group D were adult students who attended evening classes.

Table 2. Participant's profile

\begin{tabular}{llccccccc}
\hline \multicolumn{1}{c}{ Groups } & \multicolumn{2}{c}{$\begin{array}{c}\text { Group A } \\
(\mathrm{n}=27)\end{array}$} & \multicolumn{2}{c}{$\begin{array}{c}\text { Group B } \\
(\mathrm{n}=18)\end{array}$} & \multicolumn{2}{c}{ Group C } & \multicolumn{2}{c}{ Group D } \\
\multicolumn{1}{c}{ Sex } & $\mathrm{f}$ & $\%$ & $\mathrm{f}$ & $\%$ & $\mathrm{f}$ & $\%$ & $\mathrm{f}$ & $\%$ \\
\hline Female & 0 & 0 & 18 & 100 & 10 & 56 & 3 & 60 \\
Male & 27 & 100 & 0 & 0 & 8 & 44 & 2 & 40 \\
\hline
\end{tabular}

\subsection{Data Analysis}

Data obtained from the questionnaire focused on two aspects:

i) the educational value of learning activities by SMS;

ii) the evaluation of learning activities by SMS. Data collected through individual interviews and focus groups helped confirm the data obtained in the questionnaire, and gave the data reliability. 
Table 3. Educational value of learning activities by SMS

\begin{tabular}{lllllllllrrr}
\hline Items & Answer & \multicolumn{2}{c}{$\begin{array}{c}\text { Group A } \\
(\mathrm{n}=27)\end{array}$} & \multicolumn{2}{c}{$\begin{array}{c}\text { Group B } \\
(\mathrm{n}=18)\end{array}$} & \multicolumn{2}{c}{$\begin{array}{c}\text { Group C } \\
(\mathrm{n}=18)\end{array}$} & \multicolumn{2}{c}{$\begin{array}{c}\text { Group D } \\
(\mathrm{n}=5)\end{array}$} \\
& & $\mathrm{f}$ & $\%$ & $\mathrm{f}$ & $\%$ & $\mathrm{f}$ & $\%$ & $\mathrm{f}$ & \multicolumn{1}{c}{$\%$} \\
\hline Receiving stories and fables & Yes & 11 & 41 & 10 & 56 & 14 & 78 & 5 & 100 \\
motivated reading & No & 16 & 59 & 8 & 44 & 4 & 22 & 0 & 0 \\
Receiving word definitions & Yes & 21 & 78 & 18 & 100 & 17 & 94 & 5 & 100 \\
helped to enrich vocabulary & No & 6 & 22 & 0 & 0 & 1 & 6 & 0 & 0 \\
The set of all activities & Yes & 18 & 67 & 16 & 89 & 17 & 94 & 5 & 100 \\
encouraged learning & No & 9 & 33 & 2 & 11 & 1 & 6 & 0 & 0 \\
\hline
\end{tabular}

\subsubsection{Educational Value of Learning Activities by SMS}

We asked participants about the educational value of the daily "Word of the Day", reading activities and all the other learning activities by SMS such as: stories and fables which motivated the students to read (table 3 ).

The majority of respondents in groups B (56\%) and C (78\%) and all those in group $\mathrm{D}$ found that daily reading through stories and fables motivated reading, while most of those in group A (59\%) responded negatively. Group A is composed of males; most of them (67\%) did not like studying or reading. However, $41 \%$ of them found that reading through SMS motivated them to read. This strategy may have educational potential, with regards to the motivation for reading in individuals with this profile. All participants in groups B and D as well as the majority of respondents in groups A (78\%) and C (94\%) reported that the activity "Word of the Day" helped to enrich their vocabulary. For all the activities sent by SMS, all those in group D and the majority of other respondents $(67 \% \mathrm{~A}, \mathrm{~B}, 89 \%, \mathrm{C} 94 \%)$ said it motivated them to learn.

\subsubsection{Evaluation of the SMS Learning Experience}

To evaluate the participants' reactions in relation to this learning environment by SMS, we questioned students about:

i) the satisfaction or dissatisfaction of scenario 1 learning units;

ii) the degree of difficulty of scenario 2 learning units.

5.3.2.1 Students' Reactions to the Scenario 1 Learning Units. We questioned participants about their satisfaction or dissatisfaction in receiving learning units to read and store: "Word of the Day" for the construction of a dictionary on their mobile phone, several course contents to store on the device, and thoughts for reflection (table 4).

The majority of respondents in group A (56\%), B (67\%) and C (78\%) and all those in group D liked the activity "Word of the day". These results are consistent with those obtained in other studies [6].

All respondents from group D and the majority of respondents from groups B (72\%) and $\mathrm{C}(78 \%)$ liked to receive the curricular contents, but for the majority of respondents in group A (56\%), this was irrelevant. Two students responded negatively. 
Table 4. Students' reactions to the scenario 1 learning units

\begin{tabular}{lllrlrrrrrr}
\hline Items & & \multicolumn{2}{c}{$\begin{array}{c}\text { Group A } \\
(\mathrm{n}=27)\end{array}$} & \multicolumn{2}{c}{$\begin{array}{c}\text { Group B } \\
(\mathrm{n}=18)\end{array}$} & \multicolumn{2}{c}{$\begin{array}{c}\text { Group C } \\
(\mathrm{n}=18)\end{array}$} & \multicolumn{2}{c}{$\begin{array}{c}\text { Group D } \\
(\mathrm{n}=5)\end{array}$} \\
& & $\mathrm{f}$ & $\%$ & $\mathrm{f}$ & $\%$ & $\mathrm{f}$ & $\%$ & $\mathrm{f}$ & $\%$ \\
\hline \multirow{2}{*}{$\begin{array}{l}\text { Word of the Day } \\
\text { (dictionary) }\end{array}$} & Positive & 14 & 56 & 12 & 67 & 14 & 78 & 5 & 100 \\
& Indifferent & 11 & 44 & 6 & 33 & 4 & 22 & 0 & 0 \\
Curricular contents & Negative & 0 & 0 & 0 & 0 & 0 & 0 & 0 & 0 \\
& Positive & 10 & 37 & 13 & 72 & 14 & 78 & 5 & 100 \\
& Indifferent & 15 & 56 & 5 & 28 & 4 & 22 & 0 & 0 \\
Thoughts & Negative & 2 & 7 & 0 & 0 & 0 & 0 & 0 & 0 \\
& Positive & 14 & 52 & 16 & 89 & 14 & 78 & 5 & 100 \\
& Indifferent & 12 & 44 & 2 & 11 & 4 & 22 & 0 & 0 \\
& Negative & 1 & 4 & 0 & 0 & 0 & 0 & 0 & 0 \\
\hline
\end{tabular}

Table 5. Degree of difficulty of the scenario 2 learning units

\begin{tabular}{|c|c|c|c|c|c|c|c|c|c|}
\hline \multirow[t]{2}{*}{ Items } & \multirow[t]{2}{*}{ Answers } & \multicolumn{2}{|c|}{$\begin{array}{c}\text { Group A } \\
(\mathrm{n}=27)\end{array}$} & \multicolumn{2}{|c|}{$\begin{array}{c}\text { Group B } \\
(\mathrm{n}=18)\end{array}$} & \multicolumn{2}{|c|}{$\begin{array}{c}\text { Group C } \\
(\mathrm{n}=18)\end{array}$} & \multicolumn{2}{|c|}{$\begin{array}{l}\text { Group D } \\
(\mathrm{n}=5)\end{array}$} \\
\hline & & $\mathrm{f}$ & $\%$ & $\mathrm{f}$ & $\%$ & $\mathrm{f}$ & $\%$ & $\mathrm{f}$ & $\%$ \\
\hline \multirow{3}{*}{$\begin{array}{l}\text { Multiple Choice (curricular } \\
\text { content) }\end{array}$} & Easy & 15 & 55 & 5 & 25 & 11 & 61 & 2 & 40 \\
\hline & Moderate & 11 & 41 & 13 & 75 & 7 & 39 & 3 & 60 \\
\hline & Demanding & 1 & 4 & 0 & 0 & 0 & 0 & 0 & 0 \\
\hline \multirow{4}{*}{$\begin{array}{l}\text { Game: Who wants to be a } \\
\text { millionaire? }\end{array}$} & Easy & 11 & 41 & 5 & 28 & 7 & 39 & 2 & 40 \\
\hline & Moderate & 14 & 52 & 11 & 61 & 11 & 61 & 3 & 60 \\
\hline & Demanding & 2 & 7 & 2 & 11 & 0 & 0 & 0 & 0 \\
\hline & Easy & 8 & 30 & 8 & 44 & 6 & 33 & 1 & 20 \\
\hline \multirow[t]{3}{*}{ Proverbs } & Moderate & 18 & 66 & 9 & 50 & 11 & 61 & 4 & 80 \\
\hline & Demanding & 1 & 4 & 1 & 6 & 1 & 6 & 0 & 0 \\
\hline & Easy & 9 & 33 & 4 & 22 & 5 & 28 & 1 & 20 \\
\hline \multirow[t]{2}{*}{ Riddles } & Moderate & 17 & 63 & 14 & 78 & 11 & 61 & 4 & 80 \\
\hline & Demanding & 1 & 4 & 0 & 0 & 2 & 11 & 0 & 0 \\
\hline \multirow{3}{*}{$\begin{array}{l}\text { Daily reading (fables } \\
\text { moral of the story) }\end{array}$} & Easy & 11 & 41 & 7 & 39 & 6 & 33 & 2 & 40 \\
\hline & Moderate & 12 & 44 & 10 & 55 & 9 & 50 & 3 & 60 \\
\hline & Demanding & 4 & 15 & 1 & 6 & 3 & 17 & 0 & 0 \\
\hline
\end{tabular}

Most participants in groups A (52\%), B (89\%) and C (78\%) and all the individuals in group D liked receiving the "Thoughts".

5.3.2.2 Degree of Difficulty of Scenario 2 Learning Units. The activities that asked students for one reply were intended to promote the reading and understanding of the different information units that were sent. In order to promote interaction between students and teachers, these activities were questions that students had to answer, so we polled students about the degree of difficulty of each activity (table 5).

The multiple choice activities with curricular content were easy for most participants in groups A $(55 \%)$ and $\mathrm{C}(61 \%)$, and moderate for the majority of respondents in groups B $(75 \%)$ and D $(60 \%)$. The game "Who wants to be a millionaire?", Proverbs and Riddles were considered moderate by the majority of respondents from all groups. A daily reading based on fables followed by the identification of the moral of 
the story was considered moderate by less than half in group A (44\%), half of respondents in group C, $55 \%$ in group B and $60 \%$ in group D. The fact that these activities had some degree of difficulty challenged the students to build knowledge. Many of them asked family members to look for other resources (Internet, books, etc.) to find the correct response.

5.3.2.3 Reaction to all Activities Sent by SMS. We asked students whether or not they liked all activities sent by SMS (table 6).

Table 6. Reaction to all activities sent by SMS

\begin{tabular}{llllllllr}
\hline $\begin{array}{l}\text { Did you like the activities by } \\
\text { SMS? }\end{array}$ & \multicolumn{2}{c}{$\begin{array}{c}\text { Group A } \\
(\mathrm{n}=27)\end{array}$} & \multicolumn{2}{c}{$\begin{array}{c}\text { Group B } \\
(\mathrm{n}=18)\end{array}$} & \multicolumn{2}{c}{$\begin{array}{c}\text { Group C } \\
(\mathrm{n}=18)\end{array}$} & \multicolumn{2}{c}{$\begin{array}{c}\text { Group D } \\
(\mathrm{n}=5)\end{array}$} \\
& $\mathrm{f}$ & $\%$ & $\mathrm{f}$ & $\%$ & $\mathrm{f}$ & $\%$ & $\mathrm{f}$ & $\%$ \\
\hline Yes & 25 & 93 & 17 & 94 & 17 & 94 & 5 & 100 \\
No & 2 & 7 & 1 & 6 & 1 & 6 & 0 & 0 \\
\hline
\end{tabular}

All respondents in group D and the majority of participants in groups A (93\%), B (94\%) and C (94\%) enjoyed all activities sent by SMS. The same satisfaction was confirmed by data collected through individual interviews and focus groups. All students interviewed stated that they enjoyed this type of learning. In individual interviews, students said they had improved their learning: "The SMS helped me learn the foreign language ... and I assimilated better the information that was sent", "I liked the SMS ... so much content ... it helped a lot"; "The SMS sent by the teacher ... in leisure time I copied it into my notebook and I learned better".

Students who carried out the collaborative activities by SMS to create a micro story through SMS, face-to-face and at adistance said they liked it because it was a different way of working in pairs. It helped them interact and solve problems.

\section{Conclusion}

In this paper we have presented a study about the development of learning languages with the support of SMS. Despite the size limitations of SMS messages, they seemed to be, in some scenarios, such as language learning, a quick and effective way of providing students with small learning units. We believe that this kind of practice can provide students and teachers with innovative learning experiences by taking advantage of the ubiquitous nature of mobile phones, the infrastructure of the SMS, and the ability to send relevant information. As noted by participants in the study, the contents were condensed and they facilitated reading and its assimilation. Receiving information broken into small units seemed to be easily understood by students [24]. In general, students liked the activities, recognised them as stimulants and felt that they promoted learning.

We must not be dazzled by technology. The teaching strategies and methods performed with technology are of utmost importance [25]. It is important that teachers promote interaction in the classroom because it has been shown that it improves learning [7], and mobile technologies enable interaction inside and outside the classroom. 
The characteristics of mobile devices allow learners to construct knowledge in different contexts and to access information anywhere, anytime. One advantage of this educational concept is the possibility of interaction (teacher-student-student). The portability of these devices allows users to take notes or collect data on an ongoing basis and at any moment. Directly on the device they can write a text, capture an image, make a video or record voice. The mobile phone is a collaborative tool that allows multiple students to work together on a task even when in remote locations, and it also promotes the engagement of learners.

Mobile devices are becoming increasingly ubiquitous, enabling their use in an educational context. The ubiquity of mobile devices will make m-learning an important way of providing education and training in the future.

Acknowledgments. Thanks to Vodafone for sponsoring the SMS by Mail service used in this study, and teacher mobile devices (mobile phone and netbook).

This research is in part funded by CIEd, University of Minho.

\section{References}

1. Lominé, L.L., Buckhingham, C.: M-learning: texting (SMS) as a teaching \& learning tool in higher arts education (2009), http: / /www. elia-artschools.org/teachers _artes/_downloads/papers/Lomine.pdf/

2. Traxler, J.: Case studies: Introduction and overview. In: Kukulska-Hulme, A., Traxler, J. (eds.) Mobile Learning: A Handbook for Educators and Trainers, pp. 70-75. Routledge, London (2005)

3. Schick, C.: The mobile lifestyle: How the fusion of the mobile and the Internet have changed the way we live, learn, and play. In: Keynote Speaker of the 6th International Conference on Mobile Learning. Melbourne, Australia (2007)

4. Kukulska-Hulme, A., Shield, L.: An Overview of Mobile Assisted Language Learning: from content delivery to supported collaboration and interaction. ReCALL 20(3), 249-252 (2008)

5. Bollen, L., Eimler, S., Hoppe, H.: SMS-based Discussions - Technology enhanced collaboration for a literature course. In: Proceedings of the 2nd IEEE International Workshop on Wireless and Mobile Technologies in Education, pp. 209-210. IEEE Computer Society, Los Alamitos (2004)

6. Levy, M., Kennedy, C.: Learning Italian via mobile SMS. In: Kukulska-Hulme, A., Traxler, J. (eds.) Mobile Learning: A Handbook for Educators and Trainers, pp. 76-83. Routledge, London (2005)

7. Markett, C., Arnedillo Sánchez, I., Weber, S., Tangney, B.: Using short message service to encourage interactivity in the classroom. Computers \& Education 46, 280-293 (2006)

8. Naismith, L.: Using text messaging to support administrative communication in higher education. Active Learning in Higher Education 8, 155-171 (2007)

9. Song, Y.: SMS enhanced vocabulary learning for mobile audiences. International Journal of Mobile Learning and Organisation 2(1), 81-98 (2008)

10. Nix, J., Russel, J., Keegan, D.: Mobile learning/SMS (Short Messaging System) academic administration kit (2005), http://www.eden-online.org/ contents/publications/SMS/Ericsson. Mobile.A5.pdf 
11. Scornavacca, E., Huff, S., Marshall, S.: Developing a SMS-based classroom interaction system. In: Proceedings of the Conference on Mobile Learning Technologies and Applications, pp. 47-54. Massey University, Auckland (2007)

12. So, S.: The development of a SMS-based teaching and learning system. Journal of Educational Technology Development and Exchange 2(1), 113-124 (2009)

13. Moura, A., Carvalho, A.: Mobile learning: two experiments on teaching and learning with mobile phones. In: Hijón-Neira, R. (ed.) Advanced Learning, pp. 89-103. In-Teh, Vukovar (2009)

14. Kukulska-Hulme, A.: Will mobile learning change language learning? ReCALL 21(2), 157-165 (2009)

15. Kukulska-Hulme, A., Traxler, J.: Mobile Learning: A Handbook for Educators and Trainers. Routledge, London (2005)

16. Faux, F., McFarlane, A., Roche, N., Facer, K.: Handhelds: learning with handheld technologies. In: Handbook for Futurelab (2006),

http://www. futurelab.org.uk/research/handbooks/05_01.htm/

17. Sharples, M.: Big issues in mobile learning. In: Report of a workshop by the Kaleidoscope Network of Excellence Mobile Learning Initiative. University of Nottingham, UK (2006)

18. Goh, T., Hooper, V.: To TxT or not to TxT: That's the puzzle. Journal of Information Technology Education 6, 441-453 (2007)

19. Pincas, A.: Using mobile phone support for use of Greek during the Olympic games 2004. International Journal of Instructional Technology \& distance Learning 1(6) (2004), http://itdl.org/Journal/Jun_04/editor.htm

20. Lu, M.: Effectiveness of vocabulary learning via mobile phone. Journal of Computer Assisted Learning 24, 515-525 (2008)

21. Thornton, P., Houser, C.: Using mobile phones in English Education in Japan. Journal of Computer Assisted Learning 21, 217-228 (2005)

22. Cavus, N., Ibrahim, D.: M-Learning: An experiment in using SMS to support learning new English language words. British Journal of Educational Technology 40(1), 78-91 (2009)

23. Yin, R.K.: Case study research: Design and methods. Sage, Newbury Park (1984)

24. Habitzel, K., Märk, T.D., Stehno, B., Prock, S.: Microlearning: Emerging concepts, practices and technologies after e-learning. In: Proceedings of Microlearning 2005 Learning \& Working in New Media. Conference Series, Innsbruck University Press (2006), http://www.microlearning.org/micropapers/microlearning2005_p roceedings_digitalversion.pdf/

25. Chisholm, L.A.: Micro-Learning in the Lifelong Learning Context. In: Proceedings of Microlearning 2005 Learning \& Working in New Media. Conference Series, Innsbruck University Press (2006), http://www.microlearning.org/micropapers/ microlearning2005_proceedings_digitalversion.pdf / 